\title{
PELATIHAN PEMANFAATAN SOFTWARE GEOGEBRA UNTUK MENUNJANG PENCAPAIAN STANDAR KOMPETENSI GURU MATEMATIKA SMP DI KECAMATAN ABANG KABUPATEN KARANGASEM
}

\author{
oleh, \\ I Putu Wisna Ariawan \\ Fakultas Matematika dan IPA \\ Universitas Pendidikan Ganesha
}

\begin{abstract}
ABSTRAK
Kegiatan pengabdian pada masyarakat ini bertujuan untuk: (1) meningkatkan pengetahuan dan kemampuan guru matematika tingkat SMP/MTs di kecamatan Abang dalam memanfaatkan Geogebra pada pembelajaran matematika, dan (2) memberi kesempatan kepada guru matematika tingkat SMP/MTs di kecamatan Abang untuk mengikuti kegiatan pendidikan dan pelatihan guna meningkatkan kompetensi pedagogik maupun kompetensi profesionalnya. Kegiatan pengabdian menggunakan metode pendidikan dan pelatihan keterampilan berupa kegiatan ceramah, tanya jawab dan simulasi. Subyek sasaran adalah guru matematika tingkat SMP/MTs se kecamatan Abang sebanyak 16 orang. Dari hasil kegiatan dapat disimpulkan bahwa (1) Berdasarkan respon peserta pelatihan yang tertuang dalam isian angket, diketahui bahwa seluruh peserta menyatakan bahwa kegiatan yang dilaksanakan sesuai dengan tujuan yang ingin disasar yakni meningkatkan pengetahuan dan kemampuan guru matematika tingkat SMP/MTs di kecamatan Abang dalam memanfaatkan Geogebra pada pembelajaran matematika, (2) Seluruh peserta terlihat sangat antusias dalam mengikuti program pelatihan. Hal ini bisa dilihat dari kehadiran seluruh peserta mulai dari awal kegiatan sampai akhir kegiatan. (3) Seluruh peserta mampu membuat sebuah proyek dengan benar berupa visualisasi suatu materi pembelajaran berbasis software Geogebra yang dapat diimplementasikan di kelas.
\end{abstract}

Kata-kata kunci: geogebra, kompetensi guru matematika SMP

\begin{abstract}
Community service activities aims to: (1) improving the knowledge and ability of mathematics teachers SMP / MTs in Abang subdistrict in using GeoGebra on mathematics learning, and (2) provide opportunities for mathematics teachers SMP / MTs in the district to participate in Abang education and training to improve pedagogical competence and professional competence. Service activities using methods such as education and skills training activities of lectures, discussion and simulation. Target subjects are math teacher SMP / MTs se Abang subdistrict many as 16 people.
\end{abstract}


From the results it can be concluded that the activities (1) Based on the response trainee questionnaire contained in the field, it is known that all participants stated that the activities carried out in accordance with the targeted objectives to improve the knowledge and ability of mathematics teachers SMP / MTs in Abang subdistrict in harness GeoGebra on mathematics learning, (2) All participants were very enthusiastic in participating in the training program. This can be seen from the presence of all the participants from the beginning of the event until the end of the activity. (3) All of the participants were able to make a project with the correct form of visualization a GeoGebra software-based learning materials that can be implemented in the classroom.

Key words: geogebra, junior high school math teacher competence

\section{Pendahuluan}

Dalam Permendiknas Nomor 16 Tahun 2007 telah ditegaskan bahwa salah satu kompetensi pedagogik yang harus dimiliki guru mata pelajaran matematika SMP/MTs adalah mampu memanfaatkan teknologi informasi dan komunikasi untuk kepentingan pembelajaran. Sementara untuk kompetensi profesional, guru mata pelajaran matematika SMP/MTs harus mampu memanfaatkan teknologi informasi dan komunikasi (TIK) untuk berkomunikasi dan mengembangkan diri. Ini menunjukkan bahwa kemampuan memanfaatkan TIK bukanlah hanya menjadi monopoli bagi guru bidang TIK saja, tetapi guru mata pelajaran matematika SMP/MTs juga wajib untuk mampu memanfaatkan TIK.

Kemajuan TIK yang begitu pesat telah membawa dampak besar dalam pembelajaran matematika. Pengaplikasian utama dari teknologi dalam pembelajaran matematika adalah adanya pengintegrasian perangkat lunak dalam pembelajaran matematika. Saat ini, penggunaan program aplikasi matematika telah memberi warna tersendiri dalam pembelajaran matematika karena telah banyak perangkat lunak yang telah dikembangkan dan dimanfaatkan dalam pembelajaran matematika. Menurut Preiner $(2008,31)$,

Computer algebra systems, dynamic geometry software, and spreadsheets are the main types of educational software currently used for mathematics teaching and learning. Each of the programs has its own advantages and is especially useful for treating a certain selection of mathematical topics or supports certain instructional approaches". 
Perangkat lunak Geogebra merupakan salah satu produk kemajuan teknologi yang saat ini banyak dimanfaatkan dalam pembelajaran matematika. Dengan berbagai keunggulan yang dimilikinya, saat ini Geogebra banyak dimanfaatkan sebagai alat bantu untuk mengkonstruksi, mendemonstrasikan atau memvisualisasikan konsepkonsep abstrak yang ada pada matematika khususnya pada bidang geometri. Perangkat lunak Geogebra sangat mudah diperoleh karena dapat diunduh secara gratis. Di samping itu, perangkat lunak Geogebra juga sangat mudah dioperasikan karena menggunakan sintaks atau perintah yang sangat sederhana. Melihat kemudahan dalam memperoleh maupun dalam pengoperasiannya, sudah selayaknya guru-guru matematika SMP/MTs mempertimbangkan untuk menggunakan perangkat lunak Geogebra dalam mengajarkan materi-materi geometri yang memang dirasakan abstrak dan sulit bagi sebagian besar siswa di tingkat SMP/MTs.

Berdasarkan pengalaman pengusul selama menjadi tutor dalam PLPG Rayon 121 Undiksha pada tahun 2012 ini, dari tahap I hingga tahap V, mayoritas peserta PLPG guru mata pelajaran matematika tingkat SMP/MTs dan bahkan di tingkat SMA/MA, dan SMK/MAK belum banyak yang mampu menguasai Geogebra dan bahkan masih banyak yang baru tahu perangkat lunak Geogebra itu, belum tahu bahwa perangkat lunak Geogebra itu adalah perangkat lunak yang gratis. Berdasarkan hasil wawancara pengusul dengan sekretaris MGMP Kecamatan Abang, I Made Bawa Mulana, MPd pada saat pelaksanaan PLPG Tahap III terungkap bahwa guru matematika tingkat SMP/MTs di kecamatan Abang, (a) sama sekali belum pernah menggunakan perangkat lunak Geogebra dalam pembelajaran matematika, (b) belum pernah mendapat kesempatan untuk menggunakan perangkat lunak Geogebra secara intensif melalui workshop maupun pelatihan, (c) melihat kemudahan dalam memperoleh maupun dalam pengoperasiannya merasa tertarik dan sangat perlu untuk memperoleh pelatihan menggunakan perangkat lunak Geogebra, dan (d) memohon kepada pengusul untuk bersedia memberikan pelatihan menggunakan perangkat lunak Geogebra.

Berdasarkan analisis situasi yang telah diuraikan di depan dapat disimpulkan bahwa guru mata pelajaran matematika tingkat SMP/MTs di kecamatan Abang belum banyak yang mampu menguasai Geogebra. Permasalahan tersebut muncul disebabkan karena minimnya pengetahuan guru tentang perangkat lunak Geogebra. Oleh karena itu, 
permasalahan yang akan ditangani melalui kegiatan pengabdian masyarakat ini adalah : (a) rendahnya pengetahuan guru matematika tingkat SMP/MTs di kecamatan Abang dalam memanfaatkan Geogebra pada pembelajaran matematika, (b) rendahnya kemampuan guru matematika tingkat SMP/MTs di kecamatan Abang dalam memanfaatkan Geogebra pada pembelajaran matematika.

Tujuan dari kegiatan pengabdian masyarakat ini secara operasional diuraikan seperti berikut. (a) Meningkatkan pengetahuan dan kemampuan guru matematika tingkat SMP/MTs di kecamatan Abang dalam memanfaatkan Geogebra pada pembelajaran matematika, (b) Memberi kesempatan kepada guru matematika tingkat SMP/MTs di kecamatan Abang untuk mengikuti kegiatan pendidikan dan pelatihan guna meningkatkan kompetensi pedagogik maupun kompetensi profesionalnya.

\section{Metode Pelaksanaan Pengabdian}

Kegiatan-kegiatan yang telah dilaksanakan sebagai bentuk realisasi pemecahan masalah dapat diuraikan seperti berikut. (a) Penyajian teori dalam bentuk makalah tentang berbagai potensi pemanfaatan geogebra dalam pembelajaran matematika. (b) Mengerjakan tugas/proyek membuat perangkat pembelajaran berbasis geogebra. (c) Mensimulasikan tugas/proyek yang telah dihasilkan, dan (d) Mengisi angket.

Kegiatan Pengabdian Masyarakat (P2M) yang dilakukan menggunakan metode berbentuk pendidikan dan pelatihan keterampilan melalui ceramah dan demonstrasi (simulasi). Untuk melihat keberhasilan pelaksanaan kegiatan perlu diadakan evaluasi. Evaluasi yang dilaksanakan dalam kegiatan ini adalah sebagai berikut. (a) Evaluasi program, dilakukan sebelum dan setelah kegiatan dilaksanakan. Evaluasi ini bertujuan untuk mengetahui apakah program kegiatan sudah sesuai dengan tujuan yang akan dilaksanakan. (b) Evaluasi proses, dilakukan pada saat kegiatan dilaksanakan. Aspek yang dievaluasi adalah kehadiran dan aktivitas peserta dalam mengikuti pelatihan. Keberhasilan dapat dilihat dari kehadiran peserta yang mencapai lebih dari $85 \%$ dan aktivitasnya selama kegiatan tinggi. (c) Evaluasi hasil, dilaksanakan pada akhir kegiatan. Aspek yang dievaluasi adalah pengetahuan dan kemampuan peserta dalam merancang perangkat pembelajaran termasuk instrumennya. 


\section{Hasil dan Pembahasan}

Pada awal kegiatan, narasumber menyajikan materi pelatihan berupa pengetahuan memanfaatkan Geogebra pada pembelajaran matematika dalam sebuah makalah yang berjudul "Berbagai Potensi Pemanfaatan Perangkat Lunak Geogebra dalam Pembelajaran Matematika". Dalam makalah ini disajikan berbagai contoh tentang pemanfaatan Geogebra dalam pembelajaran matematika. Peserta juga diberikan buku petunjuk penggunaan Geogebra untuk mempermudah peserta dalam menggunakan software Geogebra.

a. Kemudian kegiatan dilanjutkan dengan memberikan kesempatan kepada peserta untuk berlatih atau melakukan praktek secara individu membuat proyek mengembangkan perangkat pembelajaran yang dapat diimplementasikan di kelas dengan memanfaatkan software Geogebra. Salah satu hasil karya peserta disajikan pada gambar berikut.

\section{BELAH KETUPAT}

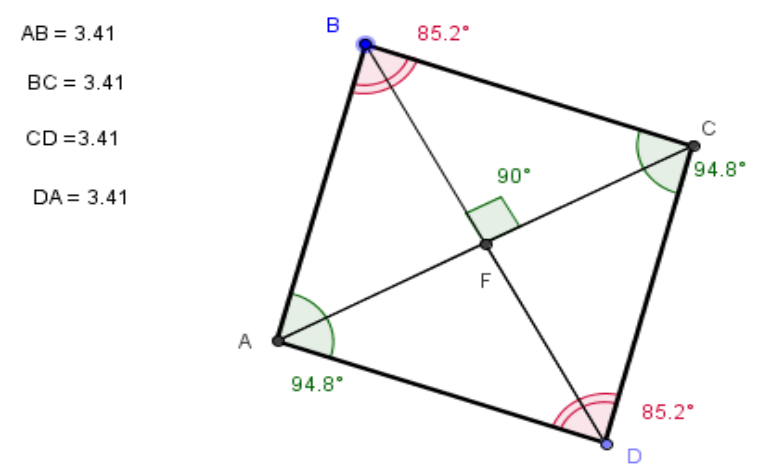

Gambar 1. Hasil Karya Proyek Salah Satu Peserta Pelatihan

Untuk menilai keberhasilan program yang dilaksanakan maka perlu dilakukan evaluasi. Berdasarkan hasil evaluasi terhadap pelaksanaan kegiatan pelatihan yang dilaksanakan diperoleh hasil sebagai berikut. (1) Berdasarkan respon peserta pelatihan yang tertuang dalam isian angket, diketahui bahwa seluruh peserta menyatakan bahwa kegiatan yang dilaksanakan sesuai dengan tujuan yang ingin disasar yakni meningkatkan pengetahuan dan kemampuan guru matematika tingkat SMP/MTs di kecamatan Abang 
dalam memanfaatkan Geogebra pada pembelajaran matematika. (2) Seluruh peserta terlihat sangat antusias dalam mengikuti program pelatihan. Hal ini bisa dilihat dari kehadiran seluruh peserta mulai dari awal kegiatan sampai akhir kegiatan. (3) Seluruh peserta mampu membuat sebuah proyek dengan benar berupa visualisasi suatu materi pembelajaran berbasis software Geogebra yang dapat diimplementasikan di kelas.

Pada saat peserta berlatih atau melakukan praktek secara individu membuat proyek mengembangkan perangkat pembelajaran berbasis software Geogebra, hampir seluruh peserta mengalami kesulitan dalam membuat sintaks atau perintah pada Geogebra. Hal ini dapat dimaklumi karena seluruh peserta belum terbiasa menggunakan software Geogebra. Untuk mengatasi masalah ini peserta diarahkan untuk melihat petunjuk pemanfaatan Geogebra yang sudah diberikan. Dengan arahan dari narasumber maka secara perlahan seluruh peserta sudah mulai bisa membuat sintaks pada Geogebra dengan baik.

Dengan adanya buku petunjuk pemanfaatan Geogebra yang diberikan dan dengan diberikannya pendampingan secara intensif maka seluruh peserta telah mampu membuat sebuah proyek sederhana yang bisa diimplementasikan di kelas pada saat pelaksanaan pembelajaran matematika. Kemampuan peserta dalam merancang perangkat pembelajaran berbasis Geogebra akan meningkat jika para guru terus berupaya berlatih menggunakan software Geogebra.

\section{Penutup}

Beberapa kesimpulan yang dapat disampaikan terkait dengan hasil pelaksanaan kegiatan dapat diuraikan seperti berikut. (a) Berdasarkan hasil evaluasi program yang dilakukan sebelum dan setelah kegiatan dilaksanakan, program kegiatan yang dirancang ternyata sudah sesuai dengan tujuan yang ingin dicapai. (b) Berdasarkan hasil evaluasi proses, kehadiran peserta dalam kegiatan pelatihan mencapai 100\% dan aktivitasnya selama kegiatan sangat tinggi. (c) Berdasarkan evaluasi hasil yang dilaksanakan pada akhir kegiatan, semua peserta dapat menyelesaikan tugas-tugas proyek yang diberikan dengan sangat baik.

Berdasarkan hasil pelaksanaan kegiatan yang telah dilakukan maka dapat disarankan hal-hal sebagai berikut. (1) Perlu ada kegiatan pelatihan lanjutan dengan materi 
lain yang lebih luas, dan (2) Perlu ada kegiatan pengabdian sejenis misalnya dengan menyasar guru matematika SMP di tingkat kabupaten

\section{DAFTAR PUSTAKA}

Antohe, V. 2009. Limits of Educational Soft "GeoGebra" in a Criticall Constructive Review. Annals. Computer Science Series. 7th Tome 1st Fasc 2009, pp. 47-54

Aksoy, Y., Bayazit, İ. \& Soybaş, D. 2010. The Effects of GeoGebra in Conjectures and Proofs, First North American GeoGebra Conference, 27 - 28 July 2010, pp. 190195, Ithaca, New York, USA.

Arranz, M. J., Losada, R., Mora, A. J., and Sada, M. 2009. Realities from GeoGebra. MSOR Connections Vol 9 No 2 May - July 2009, pp. 17-23.

CadwalladerOlsker, T. 2011. What Do We Mean by Mathematical Proof? Journal of Humanistic Mathematics Vol 1, No 1, January 2011, pp. 33-60.

Chrysanthou, I. 2008. The Use of ICT in Primary Mathematics in Cyprus: The Case of GeoGebra. Unpublished Doctoral Thesis. London: Universitat of Cambridge.

Duval, R. 1998. Geometry from a cognitive point of view, in C. Mammana \& V., Villani (Eds.). Perspective on the Teaching of Geometry for the $21^{\text {st }}$ Centuy (pp. 3751). Dordrecht, The Netherlands: Kluwer Academic Publishers.

Forsythe, S. 2010. A Study of The Effectiveness of a Dynamic Geometry Program to Support the Learning of Geometrical Concepts of 2D Shapes. Journal of The British Society for Research into Learning Mathematics Vol. 30, Number 2, June 2010 pp. 12-17.

Godwin, S. and Sutherland, R. (2004) Whole class technology for learning mathematics: the case of functions and graphs, Education, Communication and Information, 4 (1), 131-152.

Herrera, M., Preiss, R. and Riera, G. 2008. Intellectual Amplification And Other Effects "With", "Of" And "Through" Technology In Teaching And Learning Mathematics. In Proceedings of The $11^{\text {th }}$ International Congress on Mathematical Education, DG 27, 13 - 16 July 2008, pp. 1-8. Monterrey, Mexico.

Hohenwarter, J., Hohenwarter, M., and Lavicza, Z. 2008. Introducing Dynamic Mathematics Software to Secondary School Teachers: The Case of GeoGebra. Journal. of Computers in Mathematics and Science Teaching Vol. 28, No. 2, pp.135-146.

Hohenwarter, M. and Lavicza, Z. 2008. The strength of The Community: How GeoGebra Can Inspire Technology Integration in Mathematics Teaching. MSOR Connections Vol 9 No 2 May - July 2009, pp. 3 - 5. 
Hohenwarter, J., Hohenwarter, M., and Lavicza, Z. 2008. Introducing Dynamic Mathematics Software to Secondary School Teachers: The Case of GeoGebra. Journal. of Computers in Mathematics and Science Teaching (2008) 28(2), 135146.

Hohenwarter, J. and Hohenwarter, M. 2011. Introduction to GeoGebra 4. Online. http://creativecommons.org/licenses/by-nc-sa/3.0/. Diakses tanggal 1 Desember 2011.

Iranzo, N. 2009. Influence of Dynamic Geometry Software on Plane Geometry Problem Solving Strategies, Unpublished Doctoral Thesis. Bellaterra Spain: Universitat Autònoma de Barcelona.

Karadag, Z. and McDougall, D. 2009. Dynamic Worksheets: Visual Learning with The Guidance of Polya. MSOR Connections Vol 9 No 2 May - July 2009 pp. 13-16

Lu, Y.W. A. 2008. Linking Geometry and Algebra: A Multiple-Case Study of UpperSecondary Mathematics Teachers' Conceptions and Practices of GeoGebra in England and Taiwan, Unpublished Master's thesis, Cambridge: University of Cambridge, UK

Manizade, A.G and Mason, M. 2011. Choosing Geogebra Applications Most Appropriate For Teacher's Current Geometry Classroom: Pedagogical Perspective. International Journal of Educational Studies in Mathematics, 76(1), 214-218.

Pederson, J. 1983. Why We Still Need to Teach Geometry." In Proceedings of the Fourth International Congress on Mathematical Education (Boston: Birkhauser Boston), pp. 158-159.

Preiner, J. 2008. Introducing Dynamic Mathematics Software to Mathematics Teachers: the Case of GeoGebra. Unpublished Doctoral dissertation in Mathematics Education. Faculty of Natural Sciences, Salzburg: University of Salzburg, Austria

Wisna Ariawan. 2011. Pengembangan Model dan Perangkat Pembelajaran Mata Kuliah Geometri Bidang Berbasis Open Software Geogebra untuk Meningkatkan Kemampuan Berpikir Kritis Mahasiswa. Laporan Penelitian. Singaraja: Jurusan Pendidikan Matematika FMIPA Undiksha 